\title{
Regression and Artificial Neural Network Modeling for the Prediction of Gray Leaf Spot of Maize
}

\author{
P. A. Paul and G. P. Munkvold
}

First author: Department of Plant Pathology, Iowa State University, Ames 50011; and second author: Pioneer Hi-Bred International, Johnston, IA 50131.

Accepted for publication 14 December 2004.

\begin{abstract}
Paul, P. A., and Munkvold, G. P. 2005. Regression and artificial neural network modeling for the prediction of gray leaf spot of maize. Phytopathology 95:388-396.

Regression and artificial neural network (ANN) modeling approaches were combined to develop models to predict the severity of gray leaf spot of maize, caused by Cercospora zeae-maydis. In all, 329 cases consisting of environmental, cultural, and location-specific variables were collected for field plots in Iowa between 1998 and 2002. Disease severity on the ear leaf at the dough to dent plant growth stage was used as the response variable. Correlation and regression analyses were performed to select potentially useful predictor variables. Predictors from the best 9 of 80 regression models were used to develop ANN models. A random sample of $60 \%$ of the cases was used to train the networks, and $20 \%$ each for

testing and validation. Model performance was evaluated based on coefficient of determination $\left(R^{2}\right)$ and mean square error (MSE) for the validation data set. The best models had $R^{2}$ ranging from 0.70 to 0.75 and MSE ranging from 174.7 to 202.8 . The most useful predictor variables were hours of daily temperatures between 22 and $30^{\circ} \mathrm{C}(85.50$ to $230.50 \mathrm{~h})$ and hours of nightly relative humidity $\geq 90 \%$ (122 to $330 \mathrm{~h}$ ) for the period between growth stages V4 and V12, mean nightly temperature (65.26 to $76.56^{\circ} \mathrm{C}$ ) for the period between growth stages V12 and R2, longitude $\left(90.08\right.$ to $\left.95.14^{\circ} \mathrm{W}\right)$, maize residue on the soil surface (0 to $\left.100 \%\right)$, planting date (in day of the year; 112 to 182 ), and gray leaf spot resistance rating ( 2 to 7 ; based on a 1-to- 9 scale, where $1=$ most susceptible to $9=$ most resistant).

Additional keywords: disease prediction, management.
\end{abstract}

Gray leaf spot of maize (Zea mays L.) is caused by the fungus Cercospora zeae-maydis Tehon \& E. Y. Daniels. It was first reported in 1925 in Alexander County, IL (37). For years, significant outbreaks were restricted to the mountainous regions of Virginia, Tennessee, Kentucky, and North Carolina $(15,41)$. The increased prevalence of gray leaf spot over the last 20 years coincides with the widespread adoption of conservation tillage (18), a practice which leaves a substantial amount of maize residue on the soil surface. C. zeae-maydis overwinters in infested maize residue on the soil surface $(7,31)$. Payne et al. (30) and Ward et al. (39) reported that gray leaf spot lesions appeared relatively earlier and end-of-season disease severity was higher in no-till plots than in tilled plots. According to Payne et al. (30), the early appearance of gray leaf spot lesions in no-till plots allowed for more secondary cycles and, as a result, greater end-of-season disease severity than in tilled plots.

Gray leaf spot has a strong effect on maize yield, resulting in substantial losses in many production areas (41). Yield losses due to gray leaf spot could be minimized if management strategies such as crop rotation, tillage, genetic resistance, timely planting, and fungicide application are integrated. However, these strategies are not always fully implemented. Soil conservation practices and economic constraints have led to continuous cropping of maize and a great proportion of the croplands in the U.S. Midwest being under conservation tillage, leaving more than $30 \%$ of the crop residue on the soil surface (17). In areas where no-till is predominant and gray leaf spot is endemic, the ingress of inoculum from nearby fields may lead to early disease development even in plots without maize residue on the soil surface (8).

Corresponding author: P. A. Paul; E-mail address: paul.661@ osu.edu

DOI: 10.1094/PHYTO-95-0388

(C) 2005 The American Phytopathological Society
Fungicide applications have been shown to be effective at controlling gray leaf spot and reducing yield losses, and chemical control may be profitable in grain production $(21,40)$. However, in the United States, the profit margin is usually very small and the yield gain may not be enough to offset the cost of chemical control. A single fungicide application may be profitable for gray leaf spot management in maize grown for grain in Iowa; however, the probability of profitability (achieving a positive net return with one or two fungicide applications) is strongly dependent on the yield potential and susceptibility of the hybrid planted (24). Due to the high value of the crop, fungicide application is often more profitable in maize production for seed $(22,42)$. However, sound fungicide application criteria are needed in order to achieve adequate gray leaf spot control. To be effective, fungicide applications must be made early in the season in order to protect the ear leaf and lower leaves to ensure satisfactory yield (22). The decision to use fungicide often is based on crop growth stage, history of gray leaf spot at the location, host susceptibility, and disease severity thresholds (number of lesions per leaf) at the time of fungicide application. These criteria, however, do not provide a quantitative measure of gray leaf spot severity during the critical grain-fill period when the impact of the disease is most yield limiting. If accurate predictions of late-season gray leaf spot severity are made early in the season, unnecessary fungicide application could be avoided and fungicides would be used only when warranted, making gray leaf spot management more costeffective. A prediction model based on the relationship between environmental conditions at the time of management and late-season disease severity could be used to guide management decisions.

Previous attempts to describe the relationship between lateseason gray leaf spot severity and environmental conditions through regression analysis (3) were partly hindered by the lack of sufficient understanding of the basic biology of this disease. Moderate to high temperatures and prolonged periods of high 
relative humidity generally are accepted as being favorable for gray leaf spot development $(15,35,41)$. However, the mathematical relationships between these conditions and specific stages of gray leaf spot infection cycle are not fully understood. This makes conventional modeling such as multiple regression difficult. Artificial neural networks (ANN) (4) provide an alternative or complement to conventional approaches for model development. According to Francl (12), ANNs are capable of extracting subtle patterns and deciphering complex relationships among variables even when the system being modeled is poorly understood. With ANN, the mathematical relationships describing the process being modeled do not have to be known because the network "learns" these relationships through the association of patterns between independent and dependent variables (44). In plant pathology, ANNs have been shown to perform just as well as or better than traditional multivariate approaches at classifying incidence (10) and detecting infection periods of tan spot of wheat (9) and predicting wheat scab epidemics (44).

In this article, we report the results of a 5-year project to (i) determine the relationships between environmental conditions during specific stages of maize growing season and gray leaf spot severity and (ii) develop models that predict late-season gray leaf spot severity based on early- and mid-season data in order to determine the need for fungicide application. Preliminary results were achieved in previous attempts to model the relationship between gray leaf spot severity and environmental and cultural factors using stepwise multiple regression (3). Since then, additional data have been collected, different modeling approaches and forms of representing weather data as input variables have been used, and gray leaf spot prediction models have been developed. Interim results of this study have been published (27).

\section{MATERIALS AND METHODS}

Site selection and data collection. In order to generate epidemics of differing severity and to represent as many of the various combinations of variables likely to influence the development of gray leaf spot as possible, several locations were selected in Iowa between 1998 and 2002. These locations were chosen from regions with different histories of gray leaf spot, varying cropping practices, and a range of gray leaf spot-favorable weather conditions. In all, 50 locations in 17 southern Iowa counties (between latitudes $40^{\circ} 42^{\prime} 04^{\prime \prime} \mathrm{N}$ and $42^{\circ} 12^{\prime} 60^{\prime \prime} \mathrm{N}$ ) were selected, including 13 in 1998, 11 in 1999, 10 in 2000, 11 in 2001, and 5 in 2002. Data were collected from commercial seed production fields and research plots. Three to eight maize genotypes (inbreds or hybrids) with gray leaf spot resistance ratings ranging from 2 to 7 (based on a 1-to-9 rating scale, with 1 being most susceptible and 9 being most resistant) and physiological maturity ranging from 98 to 119 days comparative relative maturity (CRM) were planted at each location. Genotypes varied among locations and years, but a few hybrids were common for most locations (Table 1). Some fields were used for a single growing season whereas others were used for several or all five growing seasons (Fig. 1). Plantings were done between 22 April (day 112 of the year) and 1 July (day 182), and plots were 12 to several hundred meters long and 2 to 18 rows wide. In general, plant populations varied from 64,000 to 79,000 plants/ha.

At each location, global coordinates, percent maize residue on the soil surface, cropping sequence, planting date (day of year), and genotype resistance and maturity rating were recorded. Genotype maturity and resistance ratings were provided by seed suppliers. Latitude and longitude were recorded using a hand-held Magellan GPS 4000 global positioning unit (Magellan Systems Corporation, San Dimas, CA). The amount of maize residue on the soil surface was estimated using a line transect method (23) as described previously $(3,26)$. Three determinations were made in each field and the average was used. Cropping sequence was de- termined by recording whether the crop planted the previous growing season was maize or soybean. The number 1 was assigned to fields where maize was the previous crop and 0 was assigned to fields where soybeans were the previous crop.

On-site weather stations consisting of self-contained dataloggers and sensors were established approximately 10 to $15 \mathrm{~m}$ from the edge of each field. At each location, all dataloggers were mounted on the same pole in a grass strip at a height of $\approx 1.5 \mathrm{~m}$ above the ground. SPECWARE dataloggers (Spectrum Technologies, Inc., Plainfield, IL) were used to record temperature $\left({ }^{\circ} \mathrm{C}\right)$ and surface wetness (on a 0 -to- 15 scale) at 30 -min intervals. The wetness sensor grids were painted with three coats of a proprietary latex paint (Bob Olson, Savannah, GA) in order to enhance sensitivity to dew periods (16). Dataloggers were mounted with the wetness sensor grids facing north at an angle of $45^{\circ}$. Relative humidity at a height of $1.5 \mathrm{~m}$ aboveground was recorded at 15-min intervals using HOBO dataloggers (Model RH Stowaway, Spectrum Technologies, in 1998; and Model H8 Pro Series, Onset Computer Corporation, Bourne, MA, in the other 4 years) placed inside radiation shields (Spectrum Technologies).

Each location was visited at 14-day intervals, at which time weather data were collected, plant growth stage was recorded, and disease severity was assessed by visually estimating the percentage of the ear leaf covered with gray leaf spot lesions. At each assessment, 10 plants of each genotype were selected arbitrarily from the center of each plot and gray leaf spot severity on the ear leaf was estimated by using standard area diagrams as visual references (25). Gray leaf spot severity (\%) on the ear leaf at the dough to dent (R4 to R5) plant growth stage (34) was used as the response variable for model development. This stage was chosen because gray leaf spot severity in the middle third of the plant (ear leaf region) at approximately the R4 to R5 plant growth stage was reported as providing the best estimate of yield loss due to this disease (14).

Data organization and input variable selection. Weather data were edited to eliminate erroneous data points (values outside the measurement ranges specified by the manufacturers of the dataloggers), substitute missing data, and generate input variables. The number of missing temperature or relative humidity data points was very small. However, due to occasional failure of the dataloggers, wetness data occasionally were lost. Therefore, a binary logistic regression model was developed to estimate surface wetness status as a function of temperature and relative humidity (28). This model predicted surface wetness with an accuracy of $87 \%$. Less than $1 \%$ of the total surface wetness data used in this study were estimated using this model.

In order to generate variables potentially more likely to represent conditions favorable for the development of gray leaf spot, weather data were summarized for four periods during the growing season. Predictive models developed for other Cercospora diseases used index values based on cumulative hours of relative humidity above a critical value while temperature was within a critical range $(6,43)$. Based on these models, similar indices were derived for gray leaf spot. The duration of favorable temperatures, relative humidity, and surface wetness $(1,2,35,38)$ were calculated for four periods during the growing season relative to the R1 (silking) plant growth stage (34). These periods were (i) 45 days before R1 until 15 days after R1, (ii) 15 days before until 15 days after R1, (iii) 30 days before R1 until R1, and (iv) 45 days before R1 until 15 days before R1. These periods were chosen because they correspond to critical primary infection periods and are considered relevant for the timing of fungicide application decisions. Under field conditions, the onset of gray leaf spot coincides with silk emergence and is believed to be influenced by plant maturity (35). For each period, cumulative hours of surface wetness, temperatures between 22 and $30^{\circ} \mathrm{C}$, and relative humidity $\geq 90$ and $\geq 95 \%$ were generated. Previous reports indicated that temperature and relative humidity (summarized as described 
above) were not significant predictors of gray leaf spot severity when used as individual variables in regression models (3); therefore, different forms of representing these variables were explored and their relationships with gray leaf spot severity were reassessed. Cumulative hours of daily (0600 to $1800 \mathrm{~h})$ and nightly (1800 to $0600 \mathrm{~h}$ ) air temperature and relative humidity within the abovementioned ranges and mean daily and nightly temperature and relative humidity were generated for each of the four periods. Cumulative daily and nightly time-duration values (TDV) (6), defined as the number of hours having both temperatures between 22 and $30^{\circ} \mathrm{C}$ and relative humidity $\geq 90 \%$, also were generated for each period. Bhatia and Munkvold (3) showed that the strength of the relationship between the environment and gray leaf spot severity improved when TDV was used as an input variable in regression models instead of temperature and relative humidity as individual variables. In all, 76 weather-related variables were created and analyzed for their usefulness as input variables for model development.

To eliminate unnecessary predictors and to avoid highly correlated predictors, a preliminary variable selection was performed based on correlation analysis of the initial 76 weather-related variables. Only the temperature, relative humidity, and surface wetness variables with the highest correlations with gray leaf spot severity were selected. In general, variables summarized for period 4 (45 days before R1 to 15 days before R1) showed the best correlation with gray leaf spot severity (Table 2). Within this period, cumulative hours of surface wetness (CLW4), cumulative hours of daily temperature (CDT4), and cumulative hours of nightly relative humidity $\geq 90 \%$ (NRH904) had the highest correlation coefficients. For period 2, mean nightly temperature

TABLE 1. Maize genotypes evaluated for gray leaf spot severity in 17 Iowa counties between 1998 and 2002 for the purpose of developing prediction models

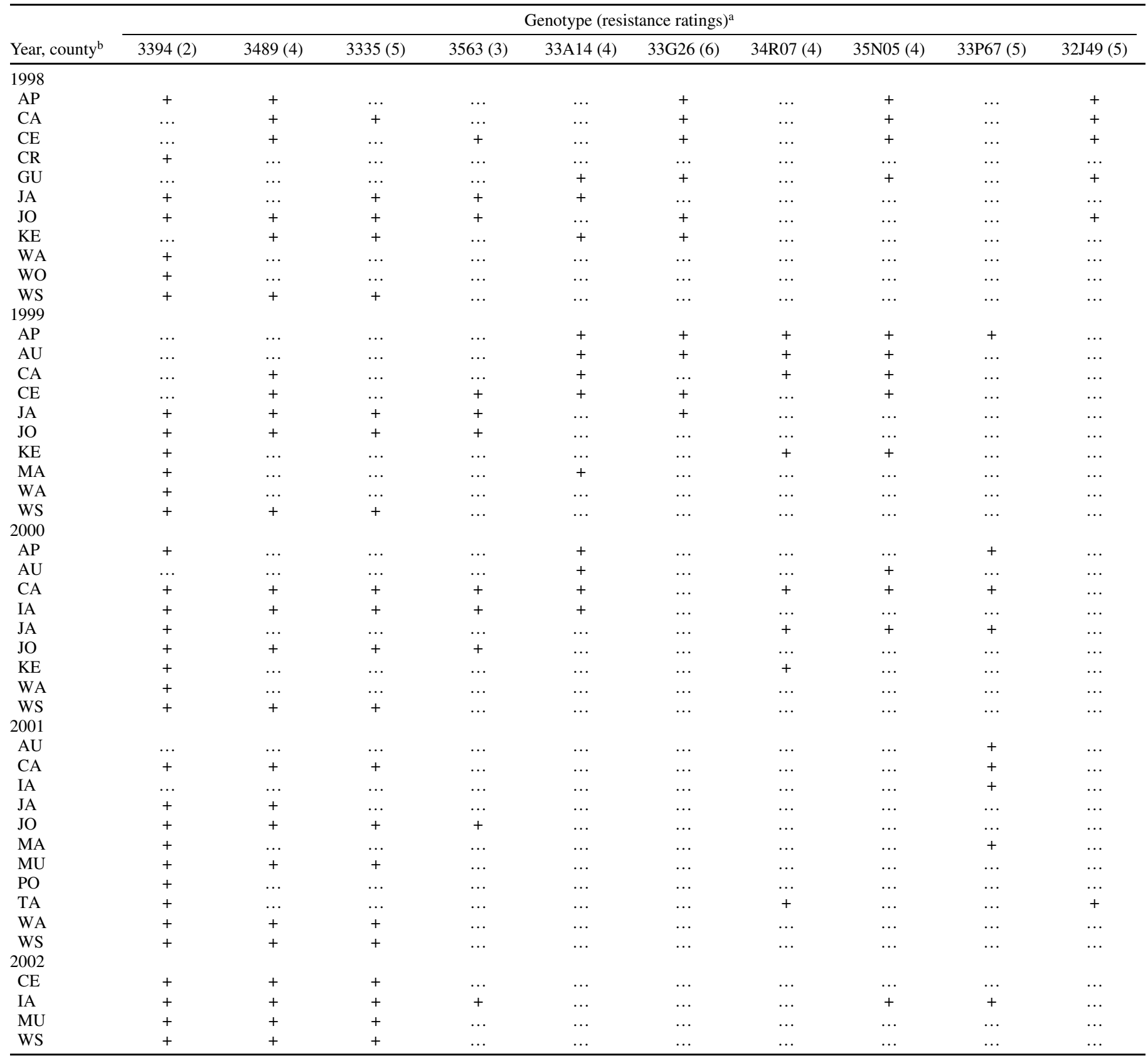

a Pioneer Brand hybrids and their corresponding gray leaf spot resistance ratings (based on a 1-to-9 scale, with 1 being most susceptible and 9 being most resistant). For convenience, genotypes planted at fewer than 6 county-years were not included in the table. Plus signs (+) indicate the county in which each hybrid was planted in a given year.

${ }^{\mathrm{b}}$ Iowa counties: $\mathrm{AP}=$ Appanoose, $\mathrm{AU}=$ Audubon, $\mathrm{CA}=\mathrm{Cass}, \mathrm{CE}=$ Cedar, $\mathrm{CR}=$ Crawford, $\mathrm{GU}=$ Guthrie, $\mathrm{IA}=\mathrm{Iowa}, \mathrm{JA}=\mathrm{Jasper}, \mathrm{JO}=\mathrm{J}$ Jones, $\mathrm{KE}=\mathrm{Keokuk}$, $\mathrm{MA}=$ Mahaska, $\mathrm{MU}=$ Muscatine, $\mathrm{PO}=$ Polk, $\mathrm{TA}=$ Tama, $\mathrm{WA}=$ Warren, $\mathrm{WO}=$ Wapello, and $\mathrm{WS}=$ Washington. 
(AVNT2) had the highest correlation coefficient. The latter variable was selected because it was thought to provide information not provided by CDT4. With the exception of AVNT2 and CDT4, no two variables representing the same weather factor were selected. In addition to weather-related variables, planting date (PD), percent maize residue on the soil surface (SR), previous crop (PC), genotype physiological maturity (MAT), genotype gray leaf spot resistance (GLSR), latitude (LAT), and longitude (LON) also were used as input variables.

Model development and validation. Regression and ANN $(4,33)$ analyses were used as complementary approaches to model the relationship between gray leaf spot severity and the predictors. As a preliminary step, Mallow's $C_{p}(20)$ variable selection criterion was used to determine the best subsets of the 11 predictor variables (selected based on correlation coefficient) to be used in

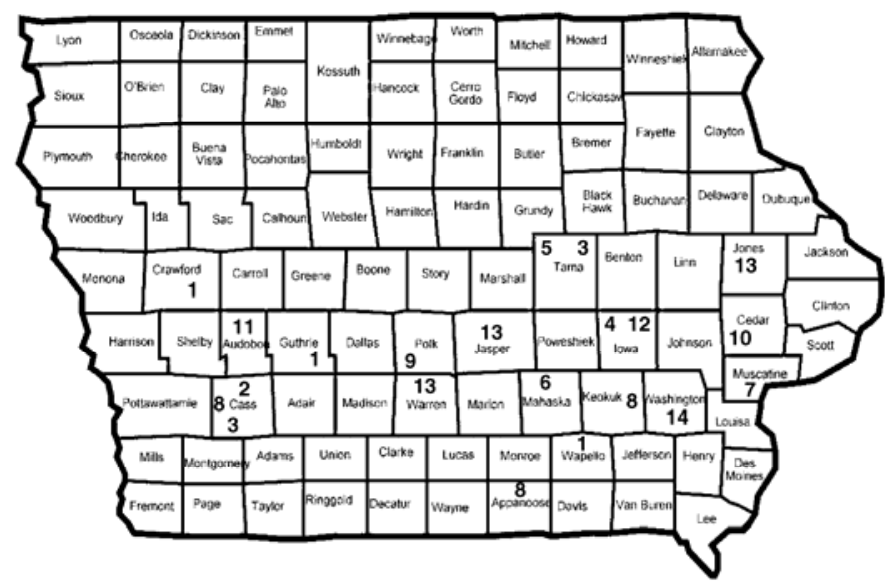

Fig. 1. Map of the state of Iowa showing the locations from which data were collected between 1998 and 2002 for the development of prediction models for gray leaf spot of maize. Data were collected from locations numbered 1 in 1998 only; 2 in 2000 only; 3 in 2001 only; 4 in 2002 only; 5 in 1998 and 2001; 6 in 1999 and 2001; 7 in 2001 and 2002; 8 in 1998, 1999, and 2000; 9 in 1998, 1999, and 2001; 10 in 1998, 1999, and 2002; 11 in 1999, 2000, and 2001; 12 in 2000, 2001, and 2002; 13 in 1998, 1999, 2000, and 2001; and 14 in all 5 years. the input layer of the ANN. Variable selection prior to model development was useful for removing redundant predictors from the model, reducing noise in the data set due to unnecessary predictors, and avoiding problems of collinearity caused by having too many interrelated variables fulfilling the same function in the model (11). To identify the best subset of potentially useful predictors, all-subsets regressions by leaps and bounds (13) were performed using the leaps function in $S$-plus 6.1 (Academic Site Edition; Insightful, Corp., Seattle, WA). Using this modeling approach, different numbers and combinations of input variables were used to develop regression models, and the best models were selected based on adjusted coefficient of determination $\left(R_{a}^{2}\right)$ and Mallow's $C_{p}$ criteria, defined as:

$$
C_{p}=\frac{R S S_{p}}{\hat{\sigma}^{2}}+2 p-n
$$

where $R S S$ is the residual sums of squares from the model with $p$ predictor variables; $\hat{\sigma}^{2}$ is the residual mean square from the model with all the predictors; and $n$ is the sample size. The model with the smallest $C_{p}$ value is considered the best model based on the $C_{p}$ criterion. In all, 80 models were developed, from which the best 9 (Table 3) were chosen. The variables selected by these analyses were used to develop ANN models.

In the second step of model development, ANN was used to model the relationship between the predictors and outcome. Like many other modeling approaches, ANN may be thought of as a minimization technique in which the goal is to minimize the difference between model output (predictions) and actual output (observations). There are several types of ANN employing different types of architectures. One of the most commonly used architectures is the feed-forward back-propagation ANN (BPNN) (4). As described by De Wolf and Francl (9) and Francl (12), a feedforward BPNN generally consists of nodes or processing elements arranged in at least three layers (input, hidden, and output). Within each layer, the nodes contain (user-defined) mathematical functions (activation functions) used to process the data before passing them on to the nodes in the adjacent layer. Each input variable is fed into the network via a separate node in the input layer. The nodes in the input layer are connected to nodes in hidden layer, and the nodes in the hidden layer are connected to

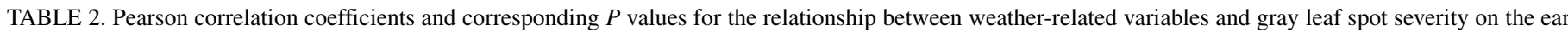
leaf at the dough to dent (R4 to R5) plant growth stage

\begin{tabular}{|c|c|c|c|c|}
\hline \multirow[b]{2}{*}{ Variable $^{b}$} & \multicolumn{4}{|c|}{ Period $^{\mathrm{a}}$} \\
\hline & 1 & 2 & 3 & 4 \\
\hline $\mathrm{CT}$ & NS & $-0.19 / 0.001$ & NS & $0.14 / 0.016$ \\
\hline CDT & $0.19 / 0.001$ & NS & NS & $0.20 / 0.001$ \\
\hline CNT & $-0.20 / 0.001$ & $-0.26 /<0.001$ & NS & NS \\
\hline AVT & NS & $-0.20 / 0.001$ & NS & $0.15 / 0.011$ \\
\hline AVDT & NS & NS & NS & $0.18 / 0.002$ \\
\hline AVNT & $-0.15 / 0.008$ & $-0.29 /<0.001$ & NS & NS \\
\hline RH90 & $0.29 /<0.001$ & $0.24 /<0.001$ & $0.24 / 0.001$ & $0.31 /<0.001$ \\
\hline DRH90 & $0.15 / 0.009$ & $0.12 / 0.033$ & NS & $0.16 / 0.007$ \\
\hline NRH90 & $0.37 /<0.001$ & $0.27 /<0.001$ & $0.31 /<0.001$ & $0.40 /<0.001$ \\
\hline RH95 & $0.26 /<0.001$ & $0.24 /<0.001$ & $0.22 /<0.001$ & $0.27 /<0.001$ \\
\hline DRH95 & $0.16 / 0.006$ & $0.15 / 0.009$ & $0.11 / 0.046$ & $0.15 / 0.008$ \\
\hline NRH95 & $0.31 /<0.001$ & $0.26 /<0.001$ & $0.27 /<0.001$ & $0.33 /<0.001$ \\
\hline AVRH & $0.23 /<0.001$ & $0.12 / 0.034$ & $0.22 / 0.001$ & $0.27 /<0.001$ \\
\hline AVDRH & $0.12 / 0.026$ & NS & $0.15 / 0.010$ & $0.16 / 0.004$ \\
\hline AVNRH & $0.36 /<0.001$ & $0.26 /<0.001$ & $0.31 /<0.001$ & $0.39 /<0.001$ \\
\hline TDV & $0.21 / 0.001$ & $-0.13 / 0.020$ & $0.30 /<0.001$ & $0.31 /<0.001$ \\
\hline DTDV & $0.19 / 0.001$ & NS & $0.17 / 0.003$ & $0.27 /<0.001$ \\
\hline NTDV & $0.18 / 0.002$ & $-0.17 / 0.004$ & $0.32 /<0.001$ & $0.32 /<0.001$ \\
\hline CLW & $0.31 /<0.001$ & $0.26 /<0.001$ & $0.24 /<0.001$ & $0.32 /<0.001$ \\
\hline
\end{tabular}

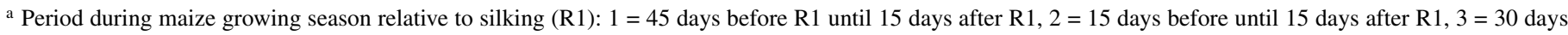
before R1 until R1, $4=45$ days before R1 until 15 days before R1, and NS = not significant.

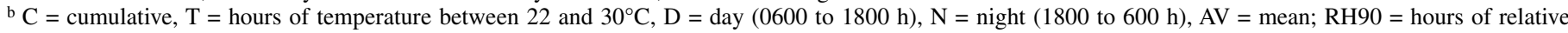
humidity $\geq 90 \%$, RH95 = hours of relative humidity $\geq 95 \%$, TDV $=$ hours with both temperature between 22 and $30{ }^{\circ} \mathrm{C}$ and relative humidity $\geq 90 \%$, and LW $=$ hours of surface wetness. 
nodes in the output layer by way of weights. Weights are analogous to coefficients in regression modeling. Information is passed (fed) through the network from the input layer to the output layer (forward) via the hidden layer and the connection weights, hence the term feed-forward. Following further processing in the output layer, network-estimated outputs are generated and compared with actual outputs, and errors are calculated (based on the difference between the actual and network outputs). The errors then are fed (propagated) backward (from output layer to input layer) through the network (error back-propagation), adjusting the connection weights so as to minimize the difference between the estimated and the actual outputs. The predictors and responses are presented to the network repeatedly (training) and, after each passage through the network, weights are adjusted. Through this iterative process, the network "learns" the relationship between the predictor and response variables and, when presented with a new set of inputs (validation), it is capable of predicting the outcome based on this relationship.

A series of BPNN with different activation functions, learning rates, momentum, initial weights, and number of hidden nodes was used to model the relationship between predictors (selected using regression models) and response (gray leaf spot severity at R4 to R5) using NeuroShell2 (Wards Systems Group, Inc., Frederick, MD). In all, 329 cases were used. A case was defined as an observation with a unique combination of year, location, and values for predictor variables. A random sample of $60 \%$ (197) of the cases was used to train the network and $20 \%$ (66) each for testing and validation. Separate sets of models were developed for each set of input variables. The network was presented with the training cases using 200,000 iterations. After every 200 iterations, the network was presented with the test data set, which was used for calibration. Linear and logistic activation functions were used in the input and output layers, respectively, while different combinations of activation functions were tested in the nodes of the hidden layers. In addition, the number of nodes in the hidden layer and the initial weights and momentum were determined by trial and error until the best model was found on the basis of the coefficient of multiple determination $\left(R^{2}\right)$ and mean square error (MSE) for the training and test sets. Training was stopped and the network was saved on the best test set; that is, when the error (difference between actual and predicted severity) for the test set was minimized. The validation cases then were used to assess the performance of the models on an independent data set. $R^{2}$ and MSE were used as measures of prediction accuracy.

\section{RESULTS}

Following preliminary variable selection, the 76 weather-related variables were reduced based on their correlation coefficients to two temperature variables and one variable each for surface wetness and relative humidity. With one exception, variables from period 4 showed the strongest correlation with gray leaf spot severity (Table 2). Among the variables for surface wetness, CLW4 had the highest correlation coefficient. NRH904 had the highest correlation coefficient of all the weather-related variables. Two temperature variables, from two growing-season stages and times during a 24-h period, were selected. CDT4, with correlation coefficient $0.20(P=0.001)$ and AVNT2, with the highest coefficient of all temperature variables, $-0.29(P<0.001)$, were selected. Among location- and genotype-related variables, LON had the highest correlation coefficient $(-0.43, P<0.001)$ followed by SR $(0.39, P<0.001)$, GLSR $(-0.37, P<0.001)$, PD $(0.32, P<$ $0.001)$, and MAT $(-0.13, P=0.022)$.

Final variable selection based on all-subsets regressions generated 80 models, of which the best 9 were selected on the basis of their relatively low Mallow's $C_{\mathrm{p}}$ values and high $R_{a}^{2}$ (Table 3). Of the 11 initial variables, 7 to 9 were selected as potentially important predictors. All the selected models identified LON, GLSR, SR, PD, AVNT2, and NRH904 as important predictors, and all but one model incorporated CDT4 as a predictor. CLW4, $\mathrm{PC}$, and MAT were the least selected of the predictor variables. Despite its relatively low individual correlation coefficient $(-0.04)$, LAT was included in four of the nine models, including one of the top three. Based on the $C_{p}$ values, models 1,2 , and 3 had the best combinations of input variables (Table 3 ).

For each subset of selected variables, a series of BPNN models was developed. The best architecture (based on prediction accu-

TABLE 4. Back-propagation artificial neural network (ANN) models developed for gray leaf spot of maize using different combinations of input variables selected based on all-subsets regressions ${ }^{\mathrm{a}}$

\begin{tabular}{lccc}
\hline ANN model $^{\mathrm{b}}$ & No. of input nodes & $R^{2}(\%)$ & MSE \\
\hline A1 & 8 & 71 & 202.77 \\
A2 & 7 & 75 & 174.75 \\
A3 & 8 & 74 & 176.84 \\
A4 & 9 & 64 & 247.83 \\
A5 & 7 & 70 & 206.42 \\
A6 & 9 & 66 & 237.43 \\
A7 & 9 & 61 & 267.81 \\
A8 & 8 & 57 & 298.27 \\
A9 & 8 & 64 & 247.32 \\
A10 & 6 & 68 & 219.83 \\
\hline
\end{tabular}

a Prediction accuracy of the models on the validation data set was based on coefficient of multiple determination $\left(R^{2}\right)$ and mean square error (MSE).

b Back-propagation ANN models developed using data collected in Iowa between 1998 and 2002. The models A1 to A9 were developed using the nine subsets of variables selected (based Mallow's $C_{p}$ value) using allsubsets regression (Table 3), while model A10 was developed following the omission of longitude from the subset of variables used in model A2.

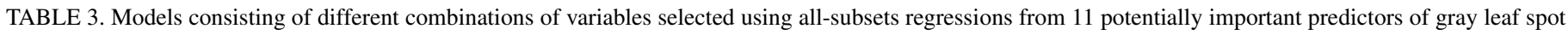
of maize

\begin{tabular}{|c|c|c|c|}
\hline Model $^{\mathrm{a}}$ & Input variables $^{b}$ & $C_{p}{ }^{\mathrm{c}}$ & $R_{a}^{2 \mathrm{~d}}$ \\
\hline 1 & LAT, LON, GLSR, SR, PD, CDT4, AVNT2, NRH904 & 7.11 & 0.416 \\
\hline 2 & LON, GLSR, SR, PD, CDT4, AVNT2, NRH904 & 7.27 & 0.414 \\
\hline 3 & LON, PC, GLSR, SR, PD, CDT4, AVNT2, NRH904 & 8.48 & 0.414 \\
\hline 4 & LAT, LON, PC, GLSR, SR, PD, CDT4, AVNT2, NRH904 & 8.50 & 0.415 \\
\hline 5 & LAT, LON, GLSR, SR, PD, AVNT2, NRH904 & 8.53 & 0.412 \\
\hline 6 & LAT, LON, GLSR, SR, PD, CLW4, CDT4, AVNT2, NRH904 & 8.66 & 0.415 \\
\hline 7 & LAT, LON, MAT, GLSR, SR, PD, CDT4, AVNT2, NRH904 & 9.03 & 0.414 \\
\hline 8 & LON, MAT, GLSR, SR, PD, CDT4, AVNT2, NRH904 & 9.07 & 0.412 \\
\hline 9 & LON, GLSR, SR, PD, CLW4, CDT4, AVNT2, NRH904 & 9.21 & 0.412 \\
\hline
\end{tabular}

a Best 9 of 80 models selected using different combinations of 11 predictors consisting of location and weather variables collected in Iowa between 1998 and 2002.

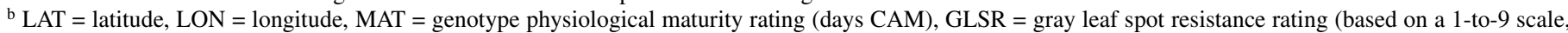
with 1 being most susceptible and 9 being most resistant), SR = maize residue on the soil surface $(\%)$, PD = planting date (day of year), CDT4 = cumulative daily temperature between 22 and $30^{\circ} \mathrm{C}$ for period 4 (maize growth stage V4 to V12), AVNT2= mean nightly temperature for period 2 (maize growth stage V12 to R2), and NRH904 = cumulative hours of nightly relative humidity $\geq 90 \%$ for period 4 .

c Mallow's $C_{p}$ value used to determine the best subset of predictors; a small $C_{p}$ value is indicative of a good subset or model.

d Adjusted coefficient of determination used to determine the best subset of predictors. 
racy on the training and test sets) was a fully connected threelayer, feed-forward network with three hidden nodes, each having a different activation function. This architecture was used for all the networks and their prediction accuracy was assessed on the same set of validation cases. In general, the networks with the highest prediction accuracy (highest $R^{2}$ ) and the smallest MSE (Table 4) coincided closely with the subset of variables with the smallest Mallow's $C_{p}$ values in linear regression models (Table 3). The best three subsets resulted in networks with the highest prediction accuracy. Seven- and eight-input networks generally performed better that nine-input networks. Network A2, with seven input variables (LON, GLSR, SR, PD, CDT4, AVNT2, and NRH904), was the most superior, with an $R^{2}$ of 0.75 . This network also had the smallest MSE and the strongest positive relationship between actual and predicted gray leaf spot severity (Fig. $2)$. The addition of $P C$ to network $A 2$ resulted in model $A 3$, with similar prediction accuracy $\left(R^{2}=0.74\right)$. The use of LAT in network A1 resulted in slightly inferior prediction accuracy $\left(R^{2}=\right.$
0.71) relative to model A2. The substitution of LAT in model A5 for CDT4 in model A2 also resulted in inferior predicted accuracy $\left(R^{2}=0.70\right)$. Model A2 was modified by removing LON to develop a tenth model (A10) using only six input variables. This model gave an $R^{2}$ of 0.68 , being superior to all of the nine-input models and two of the eight-input models.

The best six models (A1, A2, A3, A5, A6, and A10) tended to underestimate disease severity at high actual severities and overestimate severity at low actual severities (Fig. 2). For these models, between 65 and $77 \%$ of the errors for the validation data set were within $\pm 10 \%$ and between 82 and $89 \%$ within $\pm 20 \%$ of measured gray leaf spot severity (Fig. 3). Generally, models developed using MAT and CLW4 as input variables were among the most inferior in terms of prediction accuracy. Overall, ANN models developed using the best subsets of predictor variables (according to Mallow's $C_{p}$ ) (models 1, 2, and 3) (Table 3) took less time to converge than those developed using other combinations of inputs.
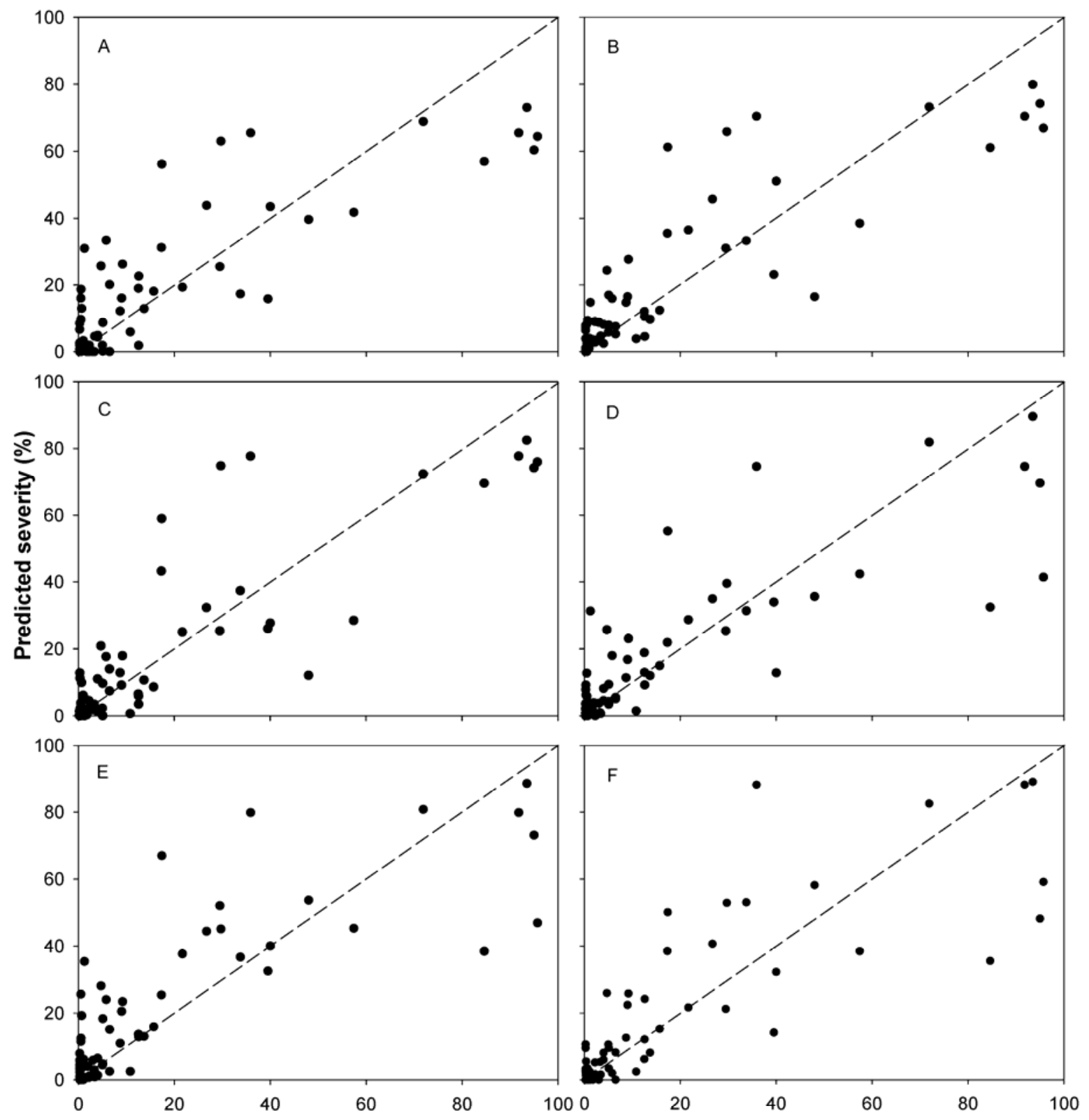

Actual severity (\%)

Fig. 2. Relationship between actual and back-propagation artificial neural network-predicted severity of gray leaf spot of maize for the validation data set for models A, A1, B, A2, C, A3, D, A5, E, A6, and F, A10. Models were developed using different combinations of predictor variables selected using all-subsets regression. 


\section{DISCUSSION}

The rationale behind the use of early- and mid-season information to predict late-season gray leaf spot severity lies in the fact that this disease can be characterized as a polycyclic disease with very few secondary cycles and strongly influenced by conditions favorable for initial inoculum production and initial infection. Studying the progress of gray leaf spot under field conditions, Ringer and Grybauskas (32) suggested that, because of a long latent period (LP50 = 14 to 19 days) and limited number of infection cycles, the amount of inoculum generated during the primary infection cycle was more important than the number of secondary cycles for the development of this disease. According to Campbell and Madden (5), forecast systems for diseases with these epidemiological characteristics should focus on information related to initial inoculum or disease.

The inability to successfully produce disease under controlled conditions has left many questions unanswered regarding the in- fluence of the environment on specific stages of the disease cycle such as inoculum production and infection. Thus, it was necessary to use empirical approaches in an effort to understand the relationship between the environment and disease development. The results of the study have led to a better understanding of this relationship. Relatively high daily temperature and cumulative hours of nightly relative humidity $\geq 90 \%$ during the beginning of the growing season were highly correlated with disease severity. Later in the season, relatively cooler nights seemed to be most favorable for disease development. This probably reflects the different effects of these variables on different stages of the disease cycle. Cumulative hours of daily (0600 to $1800 \mathrm{~h}$ ) temperatures between 22 and $30^{\circ} \mathrm{C}$ and nightly relative humidity $\geq 90 \%$ early in the growing season (between growth stages V4 and V15), and mean nightly temperatures (AVNT2) between V12 and R2 were highly correlated with gray leaf spot severity assessed at R4 to R5. This may have been due to the fact that relatively warm, humid conditions during early stages of plant growth were neces-
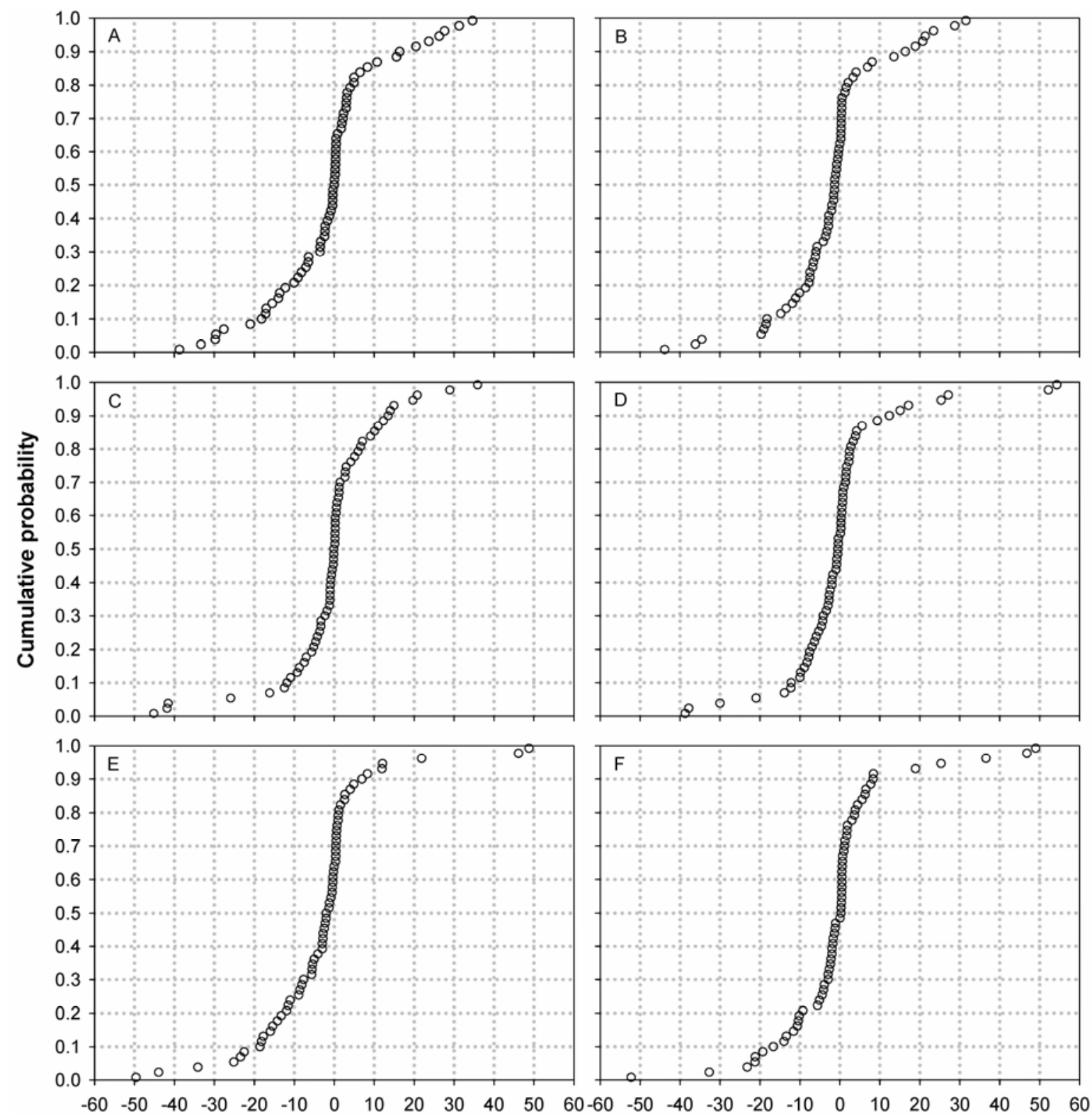

\section{Error (\% Disease severity)}

Fig. 3. Cumulative probability of percentage error between actual and back-propagation artificial neural network-predicted maize gray leaf spot severity for the validation data set for models A, A1, B, A2, C, A3, D, A5, E, A6, and F, A10. Models were developed using different combinations of input variables selected using all-subsets regression. 
sary for the production of inoculum in infected residue on the soil. Studies on the effects of temperature and relative humidity on the production of spores on diseased tissue support this idea (26). Spores were produced at temperatures between 20 and $30^{\circ} \mathrm{C}$ once relative humidity was $>90 \%$. The significant negative correlation between AVNT2 and gray leaf spot severity and positive correlation between NRH902 and gray leaf spot severity suggest that relatively cool, humid nights may have been necessary for infection to occur during period 2 (growth stage V12 to R2). Relatively cool night temperature along with high relative humidity may have been the conditions prevalent in the mountainous regions and river bottom fields where gray leaf spot remained endemic for decades (15).

It is the general consensus that the buildup of infected maize surface residue on the soil surface has been responsible for the increase in gray leaf spot incidence and severity over the past 20 years $(15,41)$, and the importance of planting date $(31,35)$ and genotype resistance for the development of this disease have been well documented. Payne and Waldron (31) reported that, although lesions first appeared in early-planted maize, final disease severity was greater on late-planted maize. The importance of prolonged periods of high relative humidity also is well known $(15,35,41)$. Thus, the strength of the correlations between GLSR, SR, PD, and NRH904 and gray leaf spot severity serve to corroborate earlier findings. These variables were selected within the best subset of variables used for model development. There is conflicting evidence regarding the importance of surface wetness for the development of gray leaf spot. Some reports suggest that free water was inhibitory to penetration of leaf tissue $(1,38)$, whereas other reports associate the development of the disease with locations with prolonged periods of surface wetness (35). Although surface wetness (CLW4) was positively correlated with gray leaf spot severity, it was selected as a predictor in only two of the nine models. This probably was because another moisture-related variable, possibly NRH904, was more important than surface wetness as a predictor of disease severity. NRH904 and CLW4 were highly correlated (correlation coefficient $=0.65, P<0.001$ ).

Unlike other plant pathology-related $(9,10,44)$ and non-plant pathology-related $(19,36)$ studies, the objective of this study was not to compare ANN with other modeling approaches. Our goal was to use ANN in conjunction with correlation and regression analyses to better understand the relationship between environmental factors and gray leaf spot development and to develop prediction models for gray leaf spot. As is the case with other modeling approaches, ANN has strengths and weaknesses $(19,36)$. One of the major weaknesses of ANN modeling is the fact that it is not always easy to interpret the relationship between the inputs and output based on an ANN model $(19,36)$. Performing correlation and regression analyses prior to developing ANN models provided some insight into the biological importance of the predictor variables and the relationship between these variables and gray leaf spot severity. Yang and Batchelor (44) emphasized the importance of using biologically important predictors in developing ANN models. They justified the superior performance of the ANN models used to predict appressorium formation in rice blast, seasonal progress of soybean rust, and wheat scab epidemic, stating that the prediction accuracy was very high $\left(R^{2}\right.$ as high as 0.99 ) because they were able to choose the right set of predictors due to the fact that the diseases had been widely studied. Comparing ANN and regression modeling approaches, Sargent (36) stated that regression modeling has the advantage of allowing the user to sequentially select predictors, eliminating those that do not contribute to the fit of the model.

Variable selection prior to ANN model development helped to reduce the complexity of the models, minimizing the chance of the models overfitting the data. The inclusion of unnecessary predictor variables may negatively affect the overall performance of ANN models (12). Complex networks tend to "memorize" the patterns (between inputs and output) of the training data set, becoming less able to generalize (validate poorly) when presented with an independent data set $(12,19)$. Although ANN models developed using the initial 11 predictor variables generally had higher $R^{2}$ values for the training data set than the models developed using 7 or 8 input variables, the $R^{2}$ values for the test and validation data sets were lower for complex models (11 inputs) than for the simpler models ( 7 and 8 inputs) (data not shown).

The advantages of using ANN over conventional statistical methods are that ANN automatically allows for nonlinear relationships between predictor and response variables and incorporates interaction between variables without requiring additional modeling, as in the case of standard statistical approaches $(19,36)$. In addition, ANN makes no assumption about the distribution of the variables (36). The flexibility allowed by this modeling approach in terms of choice of activation functions, number of nodes, and connections between nodes makes it possible to fit nonlinear relationships and complex interactions between variables without requiring complex transformations of variables and trial-and-error searches for interactions (19). Unlike conventional statistical models, with ANN, the form (linear or nonlinear) of the model need not be specified in advance and the mathematical relationships describing the process being modeled do not have to be known $(19,44)$. For a system like gray leaf spot of maize for which the relationships between the environment and disease development are not fully understood, ANN serves as an excellent tool for developing prediction models. Previous attempts to predict the severity of this disease using other modeling approaches $(3,27)$ yielded results inferior to those being reported in this study using ANN.

Combining regression and ANN modeling approaches, we were able to develop models to predict late-season gray leaf spot severity fairly accurately using early- and mid-season data as predictors. With predictions made early during the growing season, these models may be used to make decisions regarding fungicide application. This would allow for more timely applications when warranted. By virtue of its relative simplicity (only seven input variables) and high prediction accuracy $\left(R^{2}=0.75\right)$, model A2 would be the model of choice for predicting gray leaf spot severity. However, the development of several models using different subsets of predictors allows for some flexibility in terms of the variables needed in order to make predictions. In spite of the importance of LON as a predictor, we were able to develop a model (A10) with an $R^{2}$ of 0.68 without using this variable. This holds well for the future use of this model outside of the state of Iowa. However, further research may be needed prior to the application of these models in other maize-growing regions, because these regions may have inherent characteristics not accounted for by the variables used in model development.

A management program for gray leaf spot of maize could be developed using the disease prediction models from this study in combination with preplanting risk assessment models (29) and yield loss models (14). For example, a risk assessment model could be used to recommend a hybrid prior to planting; then, a prediction model based on in-season weather data could be used to reassess the risk of the disease in order to recommend fungicide application.

\section{ACKNOWLEDGMENTS}

This research was partially supported by Pioneer Hi-Bred International, Inc., and the United States Department of Agriculture North Central Integrated Pest Management Program. We thank D. Fischer, L. Herbers, B. Liska, G. Marley, A. Sayers, K. Weuthrich, A. Woodall, T. Hall, and B. VanKooten at Pioneer Hi-Bred International for providing sites for the study; cooperating maize growers R. Hoksbergen, T. Greiner, K. Kay, M. Moffat, and K. Brown; K. VanDee and M. Hunt of the Iowa State University Southeast Research Farm; V. Lawson of the Iowa State University Muscatine Island Research and Demonstration Farm; 
M. White and M. Carlton of Iowa State University Extension; J. Shriver, A. Bhatia; and M. Gleason of the Department of Plant Pathology at Iowa State University and P. Lipps and L. Madden of the Department of Plant Pathology at The Ohio State University for critically reviewing this manuscript.

\section{LITERATURE CITED}

1. Beckman, P. M., and Payne, G. A. 1982. External growth, penetration, and development of Cercospora zeae-maydis in corn leaves. Phytopathology $72: 810-815$.

2. Beckman, P. M., and Payne, G. A. 1983. Cultural techniques and conditions influencing growth and sporulation of Cercospora zeae-maydis and lesion development in corn. Phytopathology 73:286-289.

3. Bhatia, A., and Munkvold, G. P. 2002. Relationships of environmental and cultural factors with severity of gray leaf spot in maize. Plant Dis. 86:1127-1133.

4. Bishop, C. M. 1996. Neural Networks for Pattern Recognition. Oxford University Press, New York.

5. Campbell, C. L., and Madden, L. V. 1990. Introduction to Plant Disease Epidemiology. John Wiley \& Sons, New York.

6. Cu, R. M., and Phipps, P. M. 1993. Development of a pathogen growth response model for the Virginia peanut leaf spot advisory program. Phytopathology 83:195-201.

7. de Nazareno, N. R. X., Lipps, P. E., and Madden, L. V. 1992. Survival of Cercospora zeae-maydis in corn residue in Ohio. Plant Dis. 76:560564.

8. de Nazareno, N. R. X., Madden, L. V., and Lipps, P. E. 1993. Characterization of gray leaf spot epidemics of maize. J. Plant Dis. Prot. 100:410-425.

9. De Wolf, E. D., and Francl, L. J. 1997. Neural networks that distinguish infection periods of wheat tan spot in an outdoor environment. Phytopathology 87:83-87.

10. De Wolf, E. D., and Francl, L. J. 2000. Neural network classification of tan spot and Stagonospora blotch infection periods in a wheat field environment. Phytopathology 90:108-113.

11. Faraway, J. J. 2002. Practical Regression and ANOVA using R. The R Project for Statistical Computing. Online publication. The Comprehensive R Archive Network (CRAN).

12. Francl, L. J. 2004. Squeezing the turnip with artificial neural nets. Phytopathology 94:1007-1012

13. Furnival, G. M., an Wilson, R, W., Jr. 1974. Regressions by leaps and bounds. Technometrics 16:499-511.

14. Jenco, J. H. 1995. Epidemiology of Cercospora zeae-maydis on Zea mays in Iowa. M.S. thesis. Iowa State University, Ames.

15. Latterell, F. M., and Rossi, A. E. 1983. Gray leaf spot of corn: A disease on the move. Plant Dis. 67:842-847.

16. Lau, Y. F., Gleason, M. L., Zriba, N., Taylor, S. E., and Hinz, P. N. 2000. Effects of coating, deployment angle, and compass orientation on performance of electronic wetness sensors during dew periods. Plant Dis. 84:192-197.

17. Lipps, P. E. 1995. Gray leaf spot of corn. Pages 37-43 in: Proc. 7th. Annu. Iowa State Univ. Integr. Crop Manage. Conf. Ames.

18. Lipps, P. E. 1998. Gray leaf spot: A global threat to corn production. Online publication. APSnet Feature. Published by The American Phytopathological Society, St. Paul, MN.

19. Livingstone, D. J., Manallack, D. T., and Tetko, I. V. 1997. Data modelling with neural networks: Advantages and limitations. J. Comput.Aided Mol. Des. 11:135-142.

20. Mallows, C. L. 1973. Some comments on Cp. Technometrics 15:661-675.

21. Martinson, C. A., and Munkvold, G. P. 1995. Fungicidal control of leaf diseases in corn. Pages 243-246 in: Proc. Iowa State Univ. 7th Annu. Integr. Crop Manage. Conf. Ames.

22. Martinson, C. A., Wegulo, S. N., Rivera, C. J. M., and Nutter, F. W., Jr. 1995. Fungicidal spray program for seed corn production. Pages 71-79 in: Proc. 49th Annu. Corn Sorghum Res. Conf. Chicago.

23. Midwest Plan Service. 1992. Conservation tillage systems and management. Iowa State Univ. Publ. MWPS-45.

24. Munkvold, G. P., Martinson, C. A., Shriver, J. M., and Dixon, P. M. 2001. Probabilities for profitable fungicide use against gray leaf spot in hybrid maize. Phytopathology 91:477-484.

25. Nutter, F. W., Jr., and Litwiller, D. 1998. A computer program to generate standard area diagrams to aid raters in assessing disease severity. (Abstr.) Phytopathology 88(suppl.):S117.

26. Paul, P. A. 2003. Epidemiology and predictive management of gray leaf spot of maize. Ph.D. diss. Iowa State University, Ames.

27. Paul, P. A., and Munkvold, G. P. 2001. Regression and artificial neural network modeling for the prediction of gray leaf spot of maize. (Abstr.) Phytopathology 91(suppl.):S70.

28. Paul, P. A., and Munkvold, G. P. 2002. Estimation of leaf wetness status using a binary logistic regression model. (Abstr.) Phytopathology 92(suppl.):S64.

29. Paul, P. A., and Munkvold, G. P. 2004. A model-based approach to preplanting risk assessment for gray leaf spot of maize. Phytopathology 94:1350-1357.

30. Payne, G. A., Duncan, H. E., and Adkins, C. R. 1987. Influence of tillage on development of gray leaf spot and number of airborne conidia of Cercospora zeae-maydis. Plant Dis. 71:329-332.

31. Payne, G. A., and Waldron, J. K. 1983. Overwintering and spore release of Cercospora zeae-maydis in corn debris in North Carolina. Plant Dis. 67:87-89.

32. Ringer, C. E., and Grybauskas, A. P. 1995. Infection cycle components and disease progress of gray leaf spot on field corn. Plant Dis. 79:24-28.

33. Ripley, B. D. 1996. Pattern Recognition and Neural Networks. Cambridge University Press, New York.

34. Ritchie, S. W., Hanway, J. J., and Benson, G. O. 1992. How a corn plant develops. Spec. Rep. No. 48. Iowa State Univ. Coop. Ext. Serv. Ames.

35. Rupe, J. C., Siegel, M. R., and Hartman, J. R. 1982. Influence of environment and plant maturity on gray leaf spot of corn caused by Cercospora zeae-maydis. Phytopathology 72:1587-1591.

36. Sargent, D. J. 2001. Comparison of artificial neural networks with other statistical approaches. Cancer 91:1636-1642.

37. Tehon, L. R., and Daniels, E. 1925. Notes on the parasitic fungi of Illinois. Mycologia 17:240-249.

38. Thorson, P. R., and Martinson, C. A. 1993. Development and survival of Cercospora zeae-maydis germlings in different relative humidity environments. Phytopathology 83:153-157.

39. Ward, J. M. J., Laing, M. D., and Cairns, A. L. P. 1997. Management practices to reduce gray leaf spot of maize. Crop Sci. 37:1257-1262.

40. Ward, J. M. J., Laing, M. D., and Rijkenberg, F. H. J. 1997. Frequency and timing of fungicide applications for the control of gray leaf spot in maize. Plant Dis. 81:41-48.

41. Ward, J. M. J., Stromberg, E. L., Nowell, D. C., and Nutter, F. W., Jr. 1999. Gray leaf spot: A disease of global importance in maize production. Plant Dis. 83:884-895.

42. Wegulo, S. N., Martinson, C. A., Rivera-C., J. M., and Nutter, F. W., Jr. 1997. Model for economic analysis of fungicide usage in hybrid corn seed production. Plant Dis. 81:415-422.

43. Windels, C. E., Lamey, H. A., Hilde, D., Widner, J., and Knudsen, T. 1998. A Cercospora leaf spot model for sugar beet-in practice by industry. Plant Dis. 82:716-726.

44. Yang, X. B., and Batchelor, W. D. 1997. Modeling plant disease dynamics using neural networks. AI Appl. 11:47-55. 